\title{
MEDIAÇÃO SOCIOAMBIENTAL COMO MÉTODO ADEQUADO DE RESOLUÇÃO DE CONFLITOS PARA (RE)ESTABELECER O MÍNIMO EXISTENCIAL ECOLÓGICO NAS HIPÓTESES DE DESASTRES AMBIENTAIS
}

\section{SOCIO-ENVIRONMENTAL MEDIATION AS AN ADEQUATE CONFLICT RESOLUTION METHOD FOR (RE) ESTABLISHING THE MINIMUM ECOLOGICAL EXISTENTIAL IN THE HYPOTHESES OF ENVIRONMENTAL DISASTERS}

\author{
Josilene HeRnandes Ortolan di Pietro \\ Universidade Federal de Mato Grosso do Sul \\ lene_ortolan@hotmail.com \\ EDNILSON DONISETE MACHADO \\ Universidade Estadual do Norte do Paraná \\ edinilson.machado@uenp.edu.br \\ FERNANDO DE BRITO ALVES \\ Universidade Estadual do Norte do Paraná \\ fernandobrito@uenp.edu.br
}

Fecha de recepción: 11 de junio de 2019 / Fecha de aceptación: 5 de diciembre de 2019

RESUMO: A agenda internacional do século XXI foi marcada por discussões envolvendo a proteção do direito ao meio ambiente ecologicamente equilibrado. No direito brasileiro, a questão revelou-se à luz da constitucionalização deste direito como direito fundamental, sustentado na dignidade da pessoa humana, a partir de uma dimensão integrativa do meio ambiente, que erigiu além dos aspectos naturais, os aspectos socioeconômicos, afetos ao direito à qualidade de vida. Todavia, a relação harmônica entre desenvolvimento, economia e sustentabilidade ainda se releva frágil e desequilibrada. Para tanto, serão analisados os desastres ambientais ocorridos no Brasil nos anos de 2015 e 2019, com destaque para o tratamento dispensado às vítimas humanas e à natureza em razão dos danos socioambientais suportados. $\mathrm{O}$ objetivo é analisar a viabilidade da tutela extrajudicial como mecanismo de promoção de acesso à justiça e como forma de assegurar efetividade na prestação jurisdicional em caso de litígios advindos destes desastres, especialmente da mediação 
socioambiental, como mecanismo para se promover o mínimo existencial ecológico, enquanto premissa de que a existência de um patamar mínimo de bem-estar é indissociável do compromisso com um meio ambiente ecologicamente equilibrado. $\mathrm{O}$ método de abordagem foi o dedutivo, a partir de levantamento bibliográfico e legislativo.

RESUM: L'agenda internacional del segle XXI va estar marcada per debats sobre la protecció del dret a l'entorn ecològicament equilibrat. En la llei brasilera, el tema es va revelar a la llum de la constitucionalització d'aquest dret com un dret fonamental, basat en la dignitat de la persona humana, basat en una dimensió integradora del medi ambient, que es va erigir més enllà dels aspectes naturals, aspectes socioeconòmics, qualitat de vida. Tanmateix, la relació harmònica entre desenvolupament, economia i sostenibilitat continua sent fràgil i desequilibrada. Per fer-ho, analitzarem els desastres ambientals que es van produir al Brasil durant els anys 2015 i 2019, destacant el tractament que es va donar a les víctimes humanes i la naturalesa a causa dels danys socials i ambientals soferts. L'objectiu és analitzar la viabilitat de la tutela extrajudicial com a mecanisme per promoure l'accés a la justícia i com a manera d'assegurar l'efectivitat en la provisió jurisdiccional en cas de litigis derivats d'aquests desastres, especialment de la mediació socioambiental, com a mecanisme per promoure el mínim existencial existencial, la premissa que l'existència d'un nivell mínim de benestar és inseparable del compromís amb un entorn ecològicament equilibrat. EI mètode d'enfocament era el deductiu, basat en una enquesta bibliogràfica i legislativa.

RESUMEN: La agenda internacional del siglo XXI fue marcada por discusiones que involucra la protección del derecho al medio ambiente ecológicamente equilibrado. En el derecho brasileño, la cuestión se reveló a la luz de la constitucionalización de este derecho como derecho fundamental, sostenido en la dignidad de la persona humana, a partir de una dimensión integrativa del medio ambiente, que erigió más allá de los aspectos naturales, los aspectos socioeconómicos, afectos al derecho a la calidad de vida. Sin embargo, la relación armónica entre desarrollo, economía y sostenibilidad sigue siendo frágil y desequilibrada. Para ello, se analizarán los desastres ambientales ocurridos en Brasil en los años 2015 y 2019, con destaque para el tratamiento dispensado a las víctimas humanas ya la naturaleza en razón de los daños socioambientales soportados. El objetivo es analizar la viabilidad de la tutela 
extrajudicial como mecanismo de promoción de acceso a la justicia y como forma de asegurar efectividad en la prestación jurisdiccional en caso de litigios derivados de estos desastres, especialmente de la mediación socioambiental, como mecanismo para promover el mínimo existencial ecológico, mientras que la premisa de que la existencia de un nivel mínimo de bienestar es indisociable del compromiso con un medio ambiente ecológicamente equilibrado. El método de abordaje fue el deductivo, a partir de levantamiento bibliográfico y legislativo.

ABSTRACT: The international agenda of the twenty-first century was marked by discussions involving the protection of the right to the environment ecologically balanced. In Brazilian law, the issue was revealed in the light of the constitutionalisation of this right as a fundamental right, based on the dignity of the human person, based on an integrative dimension of the environment, which erected beyond natural aspects, socioeconomic aspects, quality of life. However, the harmonious relationship between development, economy and sustainability remains fragile and unbalanced. In order to do so, we will analyze the environmental disasters that occurred in Brazil in 2015 and 2019, highlighting the treatment given to human victims and nature due to the social and environmental damages suffered. The objective is to analyze the feasibility of extrajudicial tutelage as a mechanism to promote access to justice and as a way to ensure effectiveness in the jurisdictional provision in case of litigation arising from these disasters, especially socioenvironmental mediation, as a mechanism to promote the existential minimum ecological, while premise that the existence of a minimum level of well-being is inseparable from the commitment to an ecologically balanced environment. The method of approach was the deductive one, based on a bibliographical and legislative survey.

PALAVRAS-CHAVE: Mínimo existencial ecológico - Desastres ambientais Mediação socioambiental - Acesso à justiça

PARAULES CLAU: Mínim existencial ecològic - Desastres ambientals - Mediació socioambiental - Accés a la justícia

PALABRAS CLAVE: Mínimo existencial ecológico - Desastres ambientales Mediación socioambiental - Acceso a la justicia

KEYWORDS: Ecological existential minimum - Environmental disasters - socioenvironmental mediation - Access to justice 
SUMÁRIO: I. Introdução. II. Sociedade de risco, impactos ambientais e direito ao mínimo existencial ecológico. III. Mariana/2015, Brumadinho/2019: perdas ambientais e humanas. IV. Uso de meios consensuais para solução dos conflitos socioambientais. 1. Mediação socioambiental: mais que uma medida, a melhor alternativa. 2. Aprimorando a resolução dos conflitos: a prática utilizada para solucionar os conflitos coletivos decorrentes do desastre do Rio Doce. V. Considerações finais. VI. Referências.

\section{INTRODUÇÃO}

A discussão envolvendo a proteção do direito ao meio ambiente ecologicamente equilibrado marcou a agenda internacional do século XXI. As grandes transformações ocorridas no centenário anterior, relacionadas ao processo de globalização, levou o tema à Conferência das Nações Unidas sobre o Meio Ambiente Humano (Estocolmo, Suécia, 1972) e vinte anos depois, à Conferência das Nações Unidas sobre Meio Ambiente e Desenvolvimento (Rio de Janeiro, Brasil, 1992), cujos estudos propuseram uma releitura dos princípios internacionais de direitos humanos vinculados aos princípios e regras da tutela do meio ambiente, voltada à concretização do desenvolvimento sustentável.

A Constituição Federal de 1988 (CF/88), adotou valores que revelam o estabelecimento de um Estado Socioambiental de Direito, sustentado na dignidade da pessoa humana, a partir de uma dimensão integrativa do meio ambiente, que erigiu além dos aspectos naturais, os aspectos socioeconômicos, afetos ao direito à qualidade de vida,

Este novo modelo revela-se mais apropriado às questões ambientais hodiernas e essa construção dá-se a partir do surgimento de direitos de natureza metaindividuais, expressos principalmente na proteção do meio ambiente, que conferem uma dimensão ecológica à dignidade da pessoa humana, enquanto premissa de que a existência de um patamar mínimo de bem-estar é indissociável do compromisso com um meio ambiente ecologicamente equilibrado, direito fundamental constitucionalmente previsto no art. 225 da CF/88.

Todavia, mais de trinta anos passaram-se, novos encontros foram realizados, as discussões intensificaram tanto no âmbito nacional como internacional, mas o grande desafio de conciliar o desenvolvimento econômico com a tutela do meio ambiente ainda padece de medidas adequadas e eficazes. 
Como recorte metodológico, o presente artigo destaca dois desastres ambientais ocorridos no Brasil. O primeiro em 2015, no município de Mariana, estado de Minas Gerais, ocasionado pelo rompimento da barragem de Fundão, que pertencia à empresa de mineração Samarco S/A, e o outro em 2019, decorrente também do rompimento de barragem, a Barragem 1 da Mina Córrego do Feijão, esta de propriedade da mineradora Vale, na cidade mineira de Brumadinho. Ambos registraram impactos socioambientais imensuráveis, com a morte de centenas de pessoas e espécies animais, além da destruição da vegetação local.

E qual foi/será a resposta dada às vítimas, à sociedade e à natureza pelos impactos e danos socioambientais imprevisíveis, incalculáveis e indeterminados gerados?

O presente artigo propõe a análise da viabilidade da tutela extrajudicial como mecanismo de promoção de acesso à justiça e como forma de assegurar efetividade na prestação jurisdicional em caso de litígios advindos de desastres ambientais, especialmente a mediação socioambiental, com o objetivo de promover o mínimo existencial ecológico, enquanto premissa de que a existência de um patamar mínimo de bem-estar é indissociável do compromisso com um meio ambiente ecologicamente equilibrado. Analisa, para ilustrar o tema, práticas utilizadas por um magistrado para solucionar os conflitos coletivos decorrentes do desastre do Rio Doce. O método de abordagem foi o dedutivo, a partir de levantamento bibliográfico e legislativo.

\section{SOCIEDADE DE RISCO, IMPACTOS AMBIENTAIS E DIREITO AO MÍNIMO EXISTENCIAL ECOLÓGICO}

Os impactos gerados pelos desastres ambientais hodiernos revelam que o modelo de desenvolvimento ${ }^{1}$ praticado pela sociedade atual não corresponde ao paradigma da sustentabilidade, cujo refrão é anteder às necessidades do presente sem impossibilitar as gerações futuras de também atenderem as suas.

O que se nota é a tutela do meio ambiente dispersa e alheia às questões do desenvolvimento, "uma lacuna no debate do desenvolvimento econômico sobre as

\footnotetext{
${ }^{1} \mathrm{O}$ desenvolvimento econômico é definido por Celso Furtado como um "processo de mudança social pelo qual um número crescente de necessidades humanas - preexistentes ou criadas pela própria mudança - são satisfeitas através de uma diferenciação no sistema produtivo decorrente da introdução de inovações tecnológicas." (FURTADO, Celso. Dialética do desenvolvimento, Rio de Janeiro: Fondo de Cultura, 1964, p.29).
} 
questões ambientais", que determina a busca de uma "adaptação do próprio conceito de desenvolvimento que caminhe em consonância com a conservação do meio ambiente"2, atrelando o progresso tecnológico à questão ambiental.

A sociedade pós-moderna, caracterizada pela realidade mundial pós-industrial, passa, então, a ser denominada de "sociedade de risco", a partir da teoria apresentada pelo alemão Ulrich Beck ${ }^{3}$, que tem como eixo os riscos ambientais, advindos das decisões humanas.

Para o autor, nas sociedades pré-industriais, os riscos eram justificados pelos fenômenos da natureza, atribuídos às forças externas, com justificativas divinas e naturais, sem cunho político. Por sua vez, nas sociedades industriais e pós-industriais, os riscos são decorrentes do próprio mundo: é uma questão política e tem uma nova natureza, razão pela qual o estado, as pessoas, as organizações passam a ter responsabilidades ${ }^{4}$.

A ideia do risco deriva das sociedades que buscam inovação e mudança. Porém, representa "uma fase de desenvolvimento da sociedade moderna onde os riscos sociais, políticos, ecológicos e individuais criados pela ocasião do momento de inovação tecnológica escapam das instituições de controle e proteção da sociedade industrial"5.

Beck distingue duas categorias de risco: o abstrato, que se caracteriza pela imprevisibilidade humana, para o qual o direito ambiental destina o princípio da precaução, e o risco concreto, também chamado de potencial, que pode ser previsto pelo homem, amparado pelo princípio da prevenção. E essas situações de riscos justificam um sistema de proteção ambiental efetivo, sobretudo quanto ao sistema de responsabilização e eventual reparação por danos (potencial ou efetivamente) causados.

Para Leite e Belchior, este panorama da pós-modernidade é constantemente agravado pelas incertezas e pela invisibilidade dos riscos ecológicos, uma vez que o desenvolvimento econômico tende a ocultar as consequências negativas que

\footnotetext{
2 QUEIROZ, Julia Mello. Desenvolvimento econômico, inovação e meio ambiente: a busca por uma convergência no debate. CADERNOS do DESENVOLVIMENTO, Rio de Janeiro, v. 6, n. 9, p.143-170, jul.-dez. 2011, p. 145.

${ }^{3}$ Com a publicação do livro "A sociedade de risco" em 1986.

${ }^{4}$ BECK, Ulrich. La sociedade del riesgo global. Madrid: Siglo Veintiuno de España Editores S.A., 2002.

${ }^{5}$ BECK, Ulrich. Equívocos do globalismo, respostas à globalização. São Paulo: Paz e terra. 1999, p.32.
} 
provoca, pois o "Estado e os setores privados interessados utilizam meios e instrumentos para ocultar as origens e os efeitos do risco ecológico, com o objetivo de diminuir suas consequências", isto é, "com o fim de transmitir para a sociedade uma falsa ideia e que o risco ecológico está controlado"6, caracterizando uma "irresponsabilidade organizada", na qual apenas aos fatos convenientes são noticiados.

Nesta linha, emerge a necessidade de instrumentos jurídicos adequados à (re)organização da sociedade para discussão e tratamento dos riscos ambientais, sob à ótica da prevenção, da precaução e da participação social.

Inclusive, as regras do instituto da responsabilidade civil clamam por um novo formato, apropriadas à complexidade ambiental hodierna, para que sejam capazes de realizar a justiça social, proporcionado o ressarcimento das vítimas, a reconstituição do meio ambiente degradado em todas as suas esferas e que reprimam que novos desastres ambientais venham a ocorrer. Isso tudo em um período de tempo "razoável e adequado" ao julgamento da demanda, como mecanismo para restituir e resguardar o mínimo existencial ecológico à pessoa humana.

O conteúdo do direito ao mínimo existencial ecológico amplia a ultrapassada concepção que restringe qualidade de vida à satisfação de conquistas materiais, elevando-a à perspectiva de vida digna, da qual é correlata a fruição de um meio ambiente ecologicamente equilibrado. Sinaliza mudança e evolução nas relações sociais, em busca do bem-estar social, estado compreendido como tudo que promove qualidade de vida, em prol das gerações presentes e das futuras.

Em razão disso, deve ser compreendido a partir do paradigma do desenvolvimento sustentável, voltado à busca da compatibilização da satisfação das necessidades do presente, em manutenção das bases produtivas, sem, contudo, impedir que as futuras gerações usufruam e satisfaçam suas necessidades, contemplando a solidariedade intergeracional.

E essa dialética, na sociedade de risco, quando da ocorrência de danos advindos de desastres ambientais, somente será viabilizada e efetivamente concretizada quando

\footnotetext{
${ }^{6}$ LEITE, José Rubens Morato; BELCHIOR, Germana Parente Neiva. Dano ambiental na sociedade de risco: uma visão introdutória. In: FERREIRA, Helini Sivini; FERREIRA, Maria Lenor Paes Cavalcanti. (Org.). Dano ambiental da sociedade de risco. São Paulo: Saraiva, 2012, p. 16.
} 
os atores do sistema de justiça nacional, tanto da via judicial quando extrajudicial, adotarem práticas caracterizadas pela celeridade e resolutividade.

\section{MARIANA/2015, BRUMADINHO/2019: PERDAS AMBIENTAIS E HUMANAS}

A exploração de minérios é uma atividade marcante no território nacional, caracterizando-se como principal fonte econômica em alguns municípios. Dois desastres ambientais marcaram a história nacional na exploração da atividade de mineração, marcando um ciclo de desastres socioambientais.

Em 2015 houve o rompimento da barragem de Fundão, unidade da empresa Samarco, na cidade de Mariana, no estado de Minas Gerais, considerado o maior dano ambiental já ocorrido no Brasil, além de ser o maior desastre do gênero nos últimos cem anos, considerando o volume de rejeitos despejados, a distância percorrida pelos mesmos e o valor de investimento necessário para repor as perdas e danos causados.

A lama, repleta de rejeitos contaminados por resíduos tóxicos de produtos químicos, atingiu o Rio Doce, espalhando-se pelos municípios vizinhos e chegando ao Oceano Atlântico, provocando poluição marinha, inclusive.

A tragédia gerou o despejo de aproximadamente quarenta milhões de metros cúbicos de rejeitos de mineração ao seu redor, destruindo o distrito bairro mineiro de Bento Rodrigues, que ficava a dois quilômetros do empreendimento, tendo a lama percorrido mais de seiscentos quilômetros, comprometendo a bacia hidrográfica da região, tendo ultrapassado limites estaduais, contaminando a água, matando e desequilibrando todo ecossistema, as plantações, a infraestrutura, e, além do caos ambiental, deixou dezenove pessoas mortas e centenas de famílias desabrigadas. A barragem do Fundão era operada pela Samarco Mineração S.A., uma joint venture ${ }^{7}$ com a anglo-australiana BHP Biliton.

No final de janeiro de 2019, um novo capítulo de rompimento barragem de mineração veio à tona: agora, no complexo minerário do Rio Paraopebas, na mineira

\footnotetext{
7 Trata-se da união de empresas, com fins lucrativos, que pode ser permanente ou temporária, mantendo-se as personalidades jurídicas distintas. O objetivo é associar uma empresa estrangeira com uma empresa, para que esta auxilie aquela sedimentar-se no país, fornecendo as informações e o know-how técnico necessário para tanto. No caso da Samarco, 50\% pertence à empresa brasileira Vale do Rio Doce e a outra metade à BHP.
} 
Brumadinho, na barragem 1 da Mina do Córrego do Feijão. Até o final do mês de março de 2019, as equipes de resgate já computavam duzentas e dezesseis pessoas mortas, que foram identificadas, duzentos e trinta e um casos pendentes de identificação e restavam oitenta e nove desaparecidas. Ao todo, são quinhentos e trinta corpos ou apenas segmentos destes que foram encontrados debaixo da lama, ente eles trabalhadores, moradores e terceiros que foram atingidos. A barragem é de propriedade da empresa Vale do Rio Doce.

Sob o aspecto da perda puramente ambiental, o impacto da tragédia de Brumadinho foi menor, mas muito maior quanto às vítimas humanas fatais. $A$ barragem possuía um reservatório com volume superior a 12,7 milhões de metros cúbicos de lama, sendo classificada como de alto dano potencial. Assim, é o maior desastre da história nacional, somando-se as perdas ambientais e humanas.

Além das centenas de mortes, a tragédia provocou a contaminação da área e em seu entorno, bem como geração de problemas de saúde física e mental da população afetada, levando à desestabilização socioeconômica da região. São impactos sociais e econômicos nos municípios afetados que prejudicaram e ainda prejudicam inclusive aqueles que não foram atingidos de forma direta e não imaginavam que poderiam ser. E o que contribuiu para a ocorrência de duas tragédias socioambientais num curto espaço de tempo? Inicialmente, importante registrar que as barragens de mineração são uma espécie de empreendimento feitas para receber os rejeitos do ciclo de extração e beneficiamento de minérios.

Por ser uma prática comum do processo de produção de minérios no Brasil e pelo alto impacto socioambiental que provoca, houve a regulamentação estatal das mesmas a partir da edição da lei n. 12334/10, que instituiu Política Nacional de Segurança de Barragens (PNSB) ${ }^{8}$, com o objetivo de proporcionar o equilíbrio do meio ambiente e das pessoas que vivem ao entorno desses empreendimentos, além de visar a própria integridade das barragens.

Atualmente, são setecentas e sessenta e nove barragens de mineração existentes no território nacional, sendo que somente quatrocentas e vinte e cinco, o equivalente à

\footnotetext{
${ }^{8}$ A lei estabeleceu a Política Nacional de Segurança de Barragens destinadas à acumulação de água para quaisquer usos, à disposição final ou temporária de rejeitos e à acumulação de resíduos industriais, e criou o Sistema Nacional de Informações sobre Segurança de Barragens.
} 
pouco mais da metade, estão inseridas e são monitoradas pela referida política, o que corrobora com a ameaças de catástrofes decorrentes do rompimento de barragens no país, especialmente no estado de Minas Gerais, que acolhe duzentas e dezenove delas ${ }^{9}$.

Ambas as tragédias tiveram em comum o "soar do alarme" de histórico de problemas e riscos de rompimentos. As investigações feitas pela polícia civil bem como as do Ministério Público demonstraram tal situação.

Dentre as falhas que podem ser apontadas, indaga-se sobre o uso efetivo dos instrumentos de controle. Fracassaram? Ou seria, não foram sequer implementados/acionados? A PNSB atribui ao empreendedor, responsável pela estrutura das barragens, a tarefa de descrever os riscos e realizar o seu monitoramento, por meio da elaboração e apresentação de uma declaração de estabilidade, que pode ser confeccionada por um auditor independente ou pelo próprio órgão responsável. Referida declaração deve ser feita e entregue anualmente para os órgãos ambientais competentes e à Agência Nacional de Mineração.

O objetivo é monitorar e acompanhar as ações de segurança adotadas pelos empreendedores dessa atividade, para que possa haver gestão dos riscos e controle do poder público, face ao alcance dos danos socioambientais irreversíveis e irreparáveis que o empreendimento pode provocar.

Mas os mecanismos da política de segurança não foram suficientes para impedir o despejo de lama das barragens em comento. As duas se romperam e nenhum alerta soou para tentar minimizar os drásticos danos causados às pessoas, às bacias hidrográficas, ao ecossistema das proximidades.

No que tange às medidas emergenciais posteriores, essas também não foram suficientes para impedir que a situação se agravasse e no caso de Brumadinho, não foram adequadas (ou melhor, se quer existiram) para evitar uma nova tragédia envolvendo a mesma atividade. Como declaram Borges e Nabuco: "o risco de

\footnotetext{
9 PEREIRA, Luís Flavio; CRUZ, Gabriela de Barros; GUIMARÃES, Ricardo Morato Fiúza. Impactos do rompimento da barragem de rejeitos de Brumadinho, Brasil: uma análise baseada nas mudanças de cobertura da terra. ournal of Environmental Analysis and Progress V. 04 N. 02 (2019) 122-129.
} 
rompimento não foi corretamente identificado e não foram adotadas medidas efetivas de prevenção, mitigação e reparação"10.

Nesse contexto, em ambas as tragédias a judicialização foi o caminho eleito pelas vítimas na tentativa de se buscar a recomposição ao status quo ante e a indenização pelos danos causados. São múltiplas ações na esfera civil, movidas individual e coletivamente, além de ações criminais. Até uma ação de ação civil pública tendo no polo ativo o Rio Doce foi proposta ${ }^{11}$.

Diante das limitações do Poder Judiciário em dar uma resposta satisfatória às demandas socioambientais decorrentes dos desastres e considerando o ajuizamento de dezenas de ações judiciais (civis e criminal) tem-se que a batalha judicial pode mais atrasar do que efetivamente dar respostas e apresentar propostas.

Medidas que optem pela integralidade, imediatidade e celeridade da reparação mostram uma alternativa para dirimir conflitos provenientes do desequilíbrio socioambiental atual, como meio alternativo à judicialização dessas demandas, mas tão efetivas quantos. A ampla responsabilidade civil, criminal e administrativa das entidades que exploram atividades de alto risco socioambiental é reconhecida constitucionalmente, bem como na legislação pátria, além de haver jurisprudência sedimentada neste sentido.

Assim, fato é que as medidas judicias e todas as garantias processuais existentes para serem exercidas perante o Judiciário são importantes, mas não se revelam suficientes para a satisfação e reestabelecimento do direito fundamental ao mínimo existencial ecológico comprometido na ocorrência de tragédias socioambientais.

\section{USO DE MEIOS CONSENSUAIS PARA SOLUÇÃO DOS CONFLITOS SOCIOAMBIENTAIS}

${ }^{10}$ BORGES, Caio; NABUCO, Joana. Mariana e Brumadinho: desfazendo a barragem jurídica. 2019. Disponível em: https://www.jota.info/opiniao-e-analise/artigos/mariana-e-brumadinho-desfazendo-abarragem-juridica-05022019. Acesso em 24/02/2019.

${ }^{11}$ A Ação foi distribuída junto à 6 ${ }^{\underline{a}}$ Vara Federal da Subseção Judiciária de Belo Horizonte, Seção Judiciária de Minas Gerais, sob número 1009247-73.2017.4.01.3800. Constou como parte autora a Bacia Hidrográfica do Rio Doce em face da União e o estado mineiro, e foi representada pela Associação Pachamama, uma pessoa jurídica de direito privado, com sede no estado de Rio Grande do Sul, que atua em prol da defesa do meio ambiente. O objetivo era obter reconhecimento jurídico de bens ambientais enquanto sujeitos de direitos, como meio de aumentar a efetividade da tutela da bacia hidrográfica do Rio Doce, ampliando os legitimados. Em dezembro de 2018, foi proferida sentença indeferindo a petição inicial, fundamentada na ausência de personalidade jurídica do Rio, visto que o ordenamento jurídico brasileiro não Ihe confere tal atributo, além de haver previsão constitucional da prerrogativa do Ministério Público para defender tais interesses. 
Tragédias socioambientais como os acontecimentos de Mariana e Brumadinho demandam respostas céleres para responsabilizar os agentes causadores e tentar recompor (ao menos minimizar) as vítimas (humanas e não humanas) pelos danos suportados. Mas a celeridade deve caminhar junta com a cautela, devendo haver respeito à legislação e uma interpretação em favor dos atingidos. O sistema jurídico exerce um papel central neste percurso.

Neste contexto, restringir o acesso das vítimas à jurisdição estatal puramente adversarial não permite garantir o efetivo direito fundamental ao acesso à justiça. Cabe viabilizar novas portas para que respostas céleres e efetivas sejam devolvidas às vítimas.

Pois bem: no Brasil, foi instituída no final de 2010, pelo Conselho Nacional de Justiça $(\mathrm{CNJ})$, a "Política Judiciária Nacional de tratamento adequado dos conflitos de interesses"12, voltada à padronização do exercício de práticas consensuais. Por meio desta política pública, é conferida à Mediação a função de método adequado de resolução de conflitos, apropriada à resolução judicial no tratamento dos conflitos, e não apenas uma alternativa.

Os legitimados na defesa dos direitos difusos, como o Ministério Público Federal (MPF), agiram rapidamente por meio da propositura de medidas buscando o bloqueio de valores e indisposição de bens das empresas responsáveis. Essas medidas revelam-se importantes instrumentos emergenciais para salvaguardar os direitos das populações atingidas, como meio de assegurar a reparação dos danos causados.

Mas se foram adotadas como meio para garantir a solvência e responsabilização dos responsáveis, após um eventual ganho de causa em ações indenizatórias ajuizadas individualmente pelas vítimas, demandando do Poder Judiciário a solução de litígios distintos, mas ao mesmo tempo tão semelhantes, serão apenas mais números a

\footnotetext{
${ }^{12}$ A Resolução marca a instituição nacional do chamado "sistema multiportas", que se refere ao aparato de opções disponibilizadas aos cidadãos para que possam buscar solucionar diferentes conflitos utilizando-se de diferentes métodos. "Para bem compreender, pense em alguém que, tendo procurado o Poder Judiciário, encontre um leque de opções em que a solução "sentença judicial" passa a ser uma dentre outras; nesse cenário, aberta a porta do Judiciário, 'haveria como que uma antessala em que novas portas estariam à disposição, cada uma representando um método diferente" (TARTUCE, Fernanda. Mediação nos conflitos civis. 3. ed. rev., atual e ampl. Rio de Janeiro: Forense, São Paulo: Método, 2016, p. 68).
} 
serem enfrentados no cumprimento de metas judiciais, elevando a quantidade de processos e o tempo para serem julgados definitivamente.

De outro lado, podem servir como meio de garantir o pagamento das indenizações por meio da tentativa de solução pacíficas de demandas coletivas ou individuais, otimizando e viabilizando um deslinde mais adequado, sob à ótica temporal e econômica, deixando para acionar o Poder Judiciário somente quando não houver mais meios de se resolver.

$\mathrm{Na}$ busca da efetivação da resolução dos conflitos socioambientais, destaca-se a viabilidade dos métodos autocompositivos de solução de conflitos, cuja aplicação se dá mediante técnicas próprias, e devem ser facilitados e incentivados como mecanismo de acesso à justiça e instrumento de proporcionar o restabelecimento do mínimo existencial ecológico, indispensável à sadia qualidade de vida. Como recorte metodológico nesta nota, estabeleceu-se a adoção da mediação socioambiental.

\section{Mediação socioambiental: mais que uma medida, a melhor alternativa}

Primeiramente, oportuno explicar que na mediação, são as próprias partes envolvidas que são impulsionadas a encontrarem a solução para a demanda. Um terceiro, mediador imparcial, é incumbido de facilitar o diálogo entre as partes, de modo a encontrar a melhor forma de resolver a questão. Trata-se de uma medida autocompositiva, por meio da qual as partes decidem a demanda ${ }^{13}$.

Atualmente, sobretudo a partir da entrada em vigor da lei n. 13105/15 (Novo Código de Processo Civil), a mediação passou a ser uma medida pacífica para solução das controvérsias estimulada. Objetiva-se desconstruir a cultura do litígio, adotando-se uma postura "mais pacificadora, com foco não apenas na solução do conflito, mas no real interesse e satisfação dos envolvidos"14.

No caso de desastres ambientais, considerando a complexidade da causa, várias sessões ditas preparatórias (ou pré-mediação) podem ser realizadas, com intuito de conduzir os mediandos à sessão final com planejamento, esclarecimentos, permitindo

\footnotetext{
${ }^{13}$ Diferentemente da arbitragem, medida na qual as partes estarão limitadas em escolher o terceiro árbitro - que ditará a decisão, as normas que regerão o caso e a instituição.

${ }^{14}$ SAATKAMP, Barbara Simone. Aplicação da mediação como meio alternativo de solução de conflitos socioambientais no direito brasileiro. 2018. 119f. Dissertação (Mestrado em Ciências Ambientais). Universidade Estadual do Oeste do Paraná - UNIOESTE, Campus Toledo. Toledo/PR, 2018, p. 56.
} 
a concretização da informação e participação ambiental, princípios corolários da defesa do meio ambiente.

Considerando a fundamentalidade da questão ambiental e a tutela do direito ao meio ambiente sob à ótica dos direitos humanos, as relações devem ser "baseadas na harmonia, porque estas são mais duradouras, sendo essa consistência muito importante, na medida em que as situações relacionadas ao meio ambiente atingem um grande número de pessoas"15. Sob este aspecto, "a mediação de conflitos, desse modo, desfoca a maneira de pensar disjuntiva (ou- ou), a fim de prevalecer um modelo de complementaridade (e-e)"16.

Ainda, um dos pontos extremamente favoráveis à prática da mediação socioambiental reside no fato de haver jurisprudência consolidada quanto à responsabilidade objetiva do empreendedor que explora determinada atividade econômica potencialmente causadora de danos, com fundamento na teoria do risco da atividade, pela qual, admite-se o pleito da reparação do dano socioambiental com a demonstração do dano e o nexo de causalidade.

Não há que se falar em elementos subjetivos. Não se discute a culpa ou dolo. Não se admite a incidência de excludentes de responsabilidade. Como fixado o entendimento do Relator Ministro Luis Felipe Salomão'17:

Para fins do art. 543-C do Código de Processo Civil: a) a responsabilidade por dano ambiental é objetiva, informada pela teoria do risco integral, sendo o nexo de causalidade o fator aglutinante que permite que o risco se integre na unidade do ato, sendo descabida a invocação, pela empresa responsável pelo dano ambiental, de excludentes de responsabilidade civil para afastar sua obrigação de indenizar; b) em decorrência do acidente, a empresa deve recompor os danos materiais e morais causados e c) na fixação da indenização por danos morais, recomendável que o arbitramento seja feito caso a caso e com moderação, proporcionalmente ao grau de culpa, ao nível socioeconômico do autor, e, ainda, ao porte da empresa, orientando-se o juiz pelos critérios sugeridos pela doutrina e jurisprudência, com razoabilidade, valendo-se de sua experiência e bom senso, atento à realidade da vida e às peculiaridades de cada caso, de modo que, de um lado, não haja enriquecimento sem causa de quem recebe a indenização e, de outro, haja efetiva compensação pelos danos morais experimentados por aquele que fora lesado.

15 FIGUEIREDO, Luciane Monduzzi. Mediação ambiental: o acesso à justiça pelo olhar da extrajudicialidade. 2013. Disponível em: http://www.publicadireito.com.br/artigos/?cod $=6822951732 \mathrm{be} 44 \mathrm{ed}$. Acesso em: 23.03.19, p. 17.

${ }^{16}$ FIGUEIREDO, op. cit., p. 17.

17 SUPERIOR TRIBUNAL DE JUSTIÇA. RECURSO ESPECIAL N. 1.374.284 - MG (2012/0108265-7). Julgamento em 27.08.2014. Disponível em: stj.jus.br. Acesso em 25.03.2019. 
Um outro ponto dos benefícios do uso da medida nas questões socioambientais reside no fato da mediação ter como objetivo enfrentar o problema que liga as pessoas envolvidas, e não as pessoas entre si. Assim, ao invés de se tornarem defensivas e reativas, as pessoas devem pensar como parceiros em busca de um acordo justo (ou próximo disso) e vantajoso para ambos os lados, empenhados em prol de solucionar problemas mútuos ${ }^{18}$.

A resistência inicialmente encontrada quanto ao uso da mediação fundamentava-se na natureza jurídica do direito ao meio ambiente ecologicamente equilibrado, enquanto direito difuso, figurando na categoria de bem indisponível. Para resolver a questão, invoca-se o próprio texto constitucional (artigo 225), no qual está contida a responsabilidade de todos em prol da defesa do meio ambiente, mitigando-se o caráter da indisponibilidade. Assim, justifica-se a utilização da mediação socioambiental, nominada de "nova gestão democrática" para Silva Junior, que discorre:

A utilização dessa nova gestão democrática, por não estar alheia a eventuais distorções, carece de mecanismos capazes de viabilizar- Ihe direcionamento adequado. Com efeito, o instituto da mediação surge como mecanismo consideravelmente apto a produzir esse direcionamento, uma vez que fomenta uma mudança de atitude nos disputantes, clarifica os interesses em jogo e propicia a criação de uma solução comum. Sua utilização, ao contrário dos métodos convencionais adjudicatórios, permite, assim, a consecução mais efetiva, justa e estável de um desenvolvimento humano digno, pautado no ideal de sustentabilidade ${ }^{19}$.

Ademais, a garantia do interesse público na defesa do meio ambiente, nos casos de utilização da mediação socioambiental em busca da recomposição dos danos causados pelos desastres, estará assegurada com a participação do representante do Ministério Público, órgão legitimado.

\section{Aprimorando a resolução dos conflitos: a prática utilizada para solucionar os conflitos coletivos decorrentes do desastre do Rio Doce}

\footnotetext{
${ }^{18}$ FISHER, Roger; URY, William; PATTON, Bruce. Como chegar ao sim: negociação de acordos sem concessões; tradução de Vera Ribeiro \& Ana Luiza Borges, 2. ed. rev. e ampl. Rio de Janeiro: Imago, 2005.

19 SILVA JUNIOR, Sidney Rosa da. A mediação aplicada a conflitos socioambientais: uma via necessária. IN: VERÇOSA, Fabiane (coordenação). Arbitragem e mediação: temas controvertidos. Rio de Janeiro: Forense, 2014, p. 393.
} 
Para ilustrar as considerações em defesa do uso da mediação, destacam-se trechos de uma palestra proferida pelo magistrado Thiago Albani ${ }^{20}$, juiz do Tribunal de Justiça do Espírito Santo, que possui ações envolvendo a tragédia de Mariana, face ao impacto no Rio Doce.

Inicialmente, o magistrado ressalta o "custo judicial" do desastre para justificar a importância de medidas complementares na resolução dos conflitos, como a mediação, expondo o grande número de ações judiciais, repentinas, que comarcas capixabas como Colatina e Linhares, banhadas pelo Rio Doce, tiveram, sem preparação para recebe-las, até porque não havia previsão do Judiciário neste sentido.

Esse impacto prejudica também pessoas que necessitam judicializar questões alheias ao desastre, pois a carga de processos para serem julgados também é elevada repentinamente. Além dos custos de um processo judicial, que nestes casos são praticamente suportados pelo orçamento público, considerando a concessão dos benefícios da gratuidade da justiça e os trâmites junto aos Juizados Especiais Cíveis.

E para minimizar este impacto, o juiz destaca ter conseguido solucionar dois terços das demandas coletivas sob sua atribuição de forma amigável e consensual, "especificamente o fornecimento de água potável para os seus habitantes e para o seu distrito de regência", e acredita "decorreu deste trabalho voltado à melhor solução pacífica, sem precedentes nos casos análogos que venho acompanhando por toda a área atingida" 21 .

Neste ponto, recomenda que "seja buscada sempre a mediação, que a empresa poluidora possa buscar e instituir em todos os municípios afetados escritórios de mediação de fácil acesso a qualquer cidadão", sempre sob acompanhamento de um defensor (público ou advogado) "para evitar uma composição que não atenda à garantia da igualdade real. Se tais escritórios de mediação fossem instituídos nos municípios ribeirinhos, a litigiosidade seria menor". 22

\footnotetext{
20 A palestra foi proferida durante a realização do seminário "Desastres Ambientais: Experiências Nacionais e Internacionais", realizado em 13 de setembro de 2017, na Fundação Getulio Vargas, no Rio de Janeiro. O conteúdo está disponível em: LEAL, Carlos Ivan Simonsen; ZILLIKENS, Klaus. Desastres Ambientais: experiências nacionais e internacionais. Rio de Janeiro: FGV PROJETOS, 2017, p. 72-79.

${ }^{21}$ ALBANI, Thiago. In: LEAL, Carlos Ivan Simonsen; ZILLIKENS, Klaus. Desastres Ambientais: experiências nacionais e internacionais. Rio de Janeiro: FGV PROJETOS, 2017, p. 76.

22 ALBANI, op. cit., p. 77.
} 
Ademais, as indenizações devem ser justas e dentro do que é devido, não mais, nem menos, deixando as pessoas satisfeitas, o que é viabilizado pela mediação, e não quando o magistrado julga.

Uma outra questão (apontada como problema) suscitada pelo magistrado está no fato das demandas em matéria socioambiental envolveram a discussão de questões técnicas, além das ambientais. $E$ a melhor solução técnica para o caso em litígio foge da atribuição e capacidade do magistrado, estando ao encargo dos órgãos técnicos estatais, instituições tecnicamente preparadas e equipadas para informar o que e de que forma pode ou não ser feito. "O juiz não é um ambientalista, nem um técnico; por isso, ele precisa dos órgãos técnicos”, destaca Albani23.

Por fim, o magistrado enuncia o impacto dos desastres ambientais também no Poder Judiciário, o que requer que a instituição se reinvente e tenha investimentos nos setores destinados a julgarem demandas que envolvam conflitos socioambientais, ante à ausência de estrutura, equipamentos e recursos humanos suficientes e especializados.

Destacadas as observações do magistrado, registra-se que no caso específico do desastre de Mariana, o juiz utilizou-se do sistema multiportas apresentado pelo atual Código de Processo Civil para solucionar os conflitos coletivos surgidos com o desastre do Rio Doce. Na ocasião, o rompimento da barragem levou ao ajuizamento de três ações civis públicas junto à Vara da Fazenda Pública na comarca de LinharesES: uma envolvendo o fornecimento de água para o município de Linhares, outra sobre o fornecimento de água para o distrito de Regência, e uma outra com objetivo de obrigar a construção de duas barragens em Linhares para proteger as lagoas de água potável.

Com as técnicas aplicadas, o juiz conseguiu julgar duas dessas três ações no período de um ano, aproximadamente, resultando na construção de obras para o tratamento da água custeadas pela Samarco.

Confirmando o já sustentado, o magistrado deixa a lição da importância de se buscar o Poder Judiciário apenas quando não houver outros meios para resolver um conflito extrajudicialmente, uma vez que o novo Judiciário está voltado e tem sido preparado

23 Idem, p. 78. 
para soluções pacíficas das disputas, dos litígios, principalmente pelas medidas consensuais, como a mediação.

\section{CONSIDERAÇÕES FINAIS}

Os desastres ambientais narrados trazem a discussão sobre meios adequados à solução de conflitos socioambientais, além de revelarem que há instrumentos jurídicos e legislação avançados para evitar essas tragédias, porém há carência quanto à fiscalização do cumprimento dessas medidas, além de demandar uma mudança de cultura em prol de uma atuação preventiva.

Constatou-se que, buscar a reparação dos danos causados nessas situações, via judicialização da questão, não é a solução mais adequada, pois carece de celeridade e efetividade, já que não compreendem todas as faces do conflito e, consequentemente, não permitem discutir e remediar o conflito por inteiro, não dando uma resposta satisfativa aos envolvidos.

A mediação socioambiental apresenta-se como medida adequada e sustentável na solução desses conflitos socioambientais, revelando-se como verdadeiro instrumento de acesso à justiça, capaz de restabelecer às partes o mínimo existencial ecológico, conforme preleciona a política pública de tratamento adequado dos conflitos instituída pelo CNJ.

Não obstante serem a celeridade e efetividade das respostas às vítimas dos desastres ambientais, fundamentais ao deslinde do conflito, os legitimados e as autoridades competentes devem atuar com prudência e cautela, pautados nos princípios que orientam o direito ambiental e à luz da legislação existente, para não soar como injustiça ou impunidade.

\section{REFERÊNCIAS}

ACSELRAD, Henri; MELLO, Cecília Campello de A.; BEZERRA, Gustavo Neves. O que é justiça ambiental. Rio de Janeiro: Garamond, 2008.

ALBANI, Thiago. In: LEAL, Carlos Ivan Simonsen; ZILLIKENS, Klaus. Desastres Ambientais: experiências nacionais e internacionais. Rio de Janeiro: FGV PROJETOS, 2017.

BECK, Ulrich. La sociedade del riesgo global. Madrid: Siglo Veintiuno de España Editores S.A., 2002. 
BECK, Ulrich. Equívocos do globalismo, respostas à globalização. São Paulo: Paz e terra. 1999.

BORGES, Caio; NABUCO, Joana. Mariana e Brumadinho: desfazendo a barragem jurídica. 2019. Disponível em: https://www.jota.info/opiniao-e-analise/artigos/marianae-brumadinho-desfazendo-a-barragem-juridica-05022019. Acesso em 24/02/2019.

BRASIL. Constituição da República Federativa do Brasil (1988). Planalto. Disponível em: <http://www.planalto.gov.br/ccivil_03/constituicao/constituicao.htm>. Acesso em: 10 jun. 2018.

FENSTERSEIFER, Tiago. Direitos fundamentais e proteção do ambiente: a dimensão ecológica da dignidade humana no marco jurídico constitucional do estado socioambiental de direito. Porto Alegre: Livraria do Advogado Editora, 2008.

FIGUEIREDO, Luciane Monduzzi. Mediação ambiental: o acesso à justiça pelo olhar da extrajudicialidade. 2013.2 Disponível http://www.publicadireito.com.br/artigos/?cod $=6822951732$ be44ed. Acesso em: 23.03.19.

FISHER, Roger; URY, William; PATTON, Bruce. Como chegar ao sim: negociação de acordos sem concessões; tradução de Vera Ribeiro \& Ana Luiza Borges, 2. ed. rev. e ampl. Rio de Janeiro: Imago, 2005.

FURTADO, Celso. Dialética do desenvolvimento, Rio de Janeiro: Fondo de Cultura, 1964.

GORETTI, Ricardo. Mediação e acesso à justiça. Salvador: JusPodivm, 2016.

LEAL, Carlos Ivan Simonsen; ZILLIKENS, Klaus. Desastres Ambientais: experiências nacionais e internacionais. Rio de Janeiro: FGV PROJETOS, 2017.

LEITE, José Rubens Morato; BELCHIOR, Germana Parente Neiva. Dano ambiental na sociedade de risco: uma visão introdutória. In: FERREIRA, Helini Sivini; FERREIRA, Maria Lenor Paes Cavalcanti. (Org.). Dano ambiental da sociedade de risco. São Paulo: Saraiva, 2012.

MANCUSO, Rodolfo de Camargo. A Resolução dos Conflitos e a Função Judicial no Contemporâneo Estado de Direito. São Paulo: Editora Revista dos Tribunais, 2009.

MILARÉ, Édis. Direito do ambiente. 9.ed. São Paulo: Revista dos Tribunais, 2014.

NALINI, José Renato. É urgente construir alternativas à Justiça. In: ZANETI JR., Hermes; CABRAL, Trícia Navarro Xavier (Coords.). Justiça Multiportas: mediação, conciliação, arbitragem e outros meios de solução adequada para conflitos. Salvador: JusPodivm, 2016, p. 33-48.

PADILHA, Norma Sueli. Fundamentos constitucionais do direito ambiental brasileiro. Rio de Janeiro: Elsevier, 2010. 
PEREIRA, Luís Flavio; CRUZ, Gabriela de Barros; GUIMARÃES, Ricardo Morato Fiúza. Impactos do rompimento da barragem de rejeitos de Brumadinho, Brasil: uma análise baseada nas mudanças de cobertura da terra. Journal of Environmental Analysis and Progress, V. 04, N. 02 (2019) 122-129.

QUEIROZ, Julia Mello. Desenvolvimento econômico, inovação e meio ambiente: a busca por uma convergência no debate. Cadernos do Desenvolvimento, Rio de Janeiro, V. 6, N. 9, p.143-170, jul.-dez. 2011.

SAATKAMP, Barbara Simone. Aplicação da mediação como meio alternativo de solução de conflitos socioambientais no direito brasileiro. 2018. 119f. Dissertação (Mestrado em Ciências Ambientais). Universidade Estadual do Oeste do Paraná UNIOParaná Campus Toledo. Toledo/PR, 2018.

SILVA JUNIOR, Sidney Rosa da. A mediação aplicada a conflitos socioambientais: uma via necessária. En: VERÇOSA, Fabiane (coordenação). Arbitragem e mediação: temas controvertidos. Rio de Janeiro: Forense, 2014.

SUPERIOR TRIBUNAL DE JUSTIÇA. RECURSO ESPECIAL N. 1.374.284 - MG (2012/0108265-7). Julgamento em 27.08.2014. Disponível em: stj.jus.br. Acesso em 25.03.2019.

TARTUCE, Fernanda. Mediação nos conflitos civis. 3. ed. rev., atual e ampl. Rio de Janeiro: Forense, São Paulo: Método, 2016. 